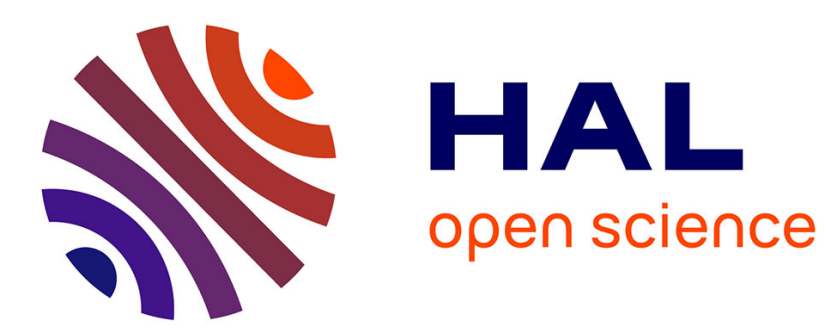

\title{
Modelling the General Public's Inflation Expectations Using the Michigan Survey Data
}

\author{
Arto Luoma, Jani Luoto
}

\section{To cite this version:}

Arto Luoma, Jani Luoto. Modelling the General Public's Inflation Expectations Using the Michigan Survey Data. Applied Economics, 2009, 41 (10), pp.1311-1320. 10.1080/00036840701604339 . hal00582034

\section{HAL Id: hal-00582034 \\ https://hal.science/hal-00582034}

Submitted on 1 Apr 2011

HAL is a multi-disciplinary open access archive for the deposit and dissemination of scientific research documents, whether they are published or not. The documents may come from teaching and research institutions in France or abroad, or from public or private research centers.
L'archive ouverte pluridisciplinaire HAL, est destinée au dépôt et à la diffusion de documents scientifiques de niveau recherche, publiés ou non, émanant des établissements d'enseignement et de recherche français ou étrangers, des laboratoires publics ou privés. 


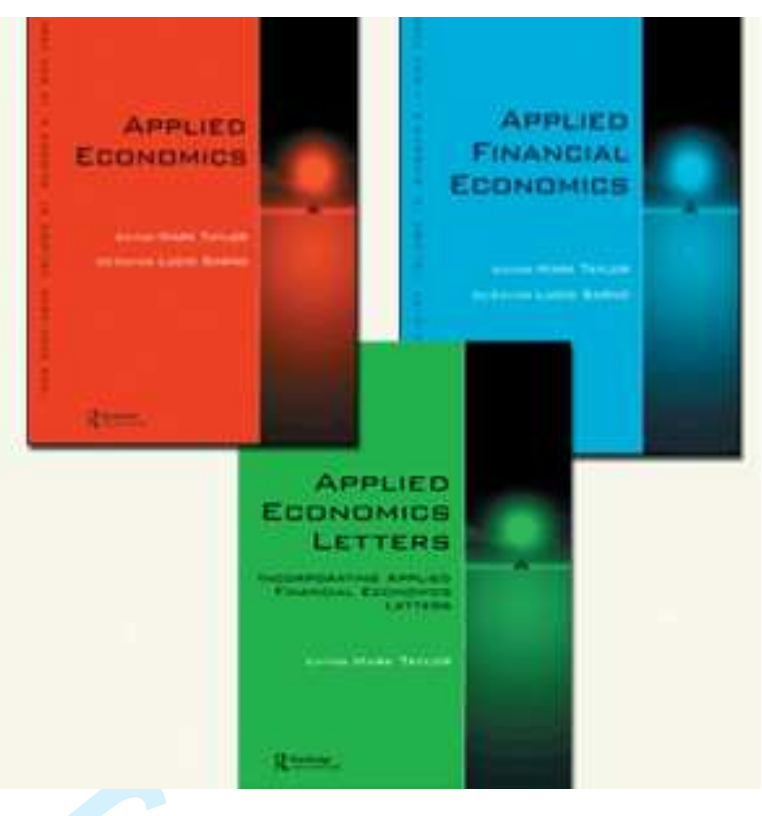

\section{Modelling the General Public's Inflation Expectations Using the Michigan Survey Data}

\begin{tabular}{|r|l|}
\hline Journal: & Applied Economics \\
\hline Manuscript ID: & APE-05-0717 \\
\hline Journal Selection: & Applied Economics \\
\hline Date Submitted by the \\
Author: & 23-Dec-2005 \\
\hline Complete List of Authors: & $\begin{array}{l}\text { Luoma, Arto; University of Tampere, Department of Mathematics, } \\
\text { Statistics and Philosophy } \\
\text { Luoto, Jani; University of Jyväskylä, School of Business and } \\
\text { Economics }\end{array}$ \\
\hline JEL Code: & $\begin{array}{l}\text { C11 - Bayesian Analysis < C1 - Econometric and Statistical } \\
\text { Methods: General < C - Mathematical and Quantitative Methods, } \\
\text { C22 - Time-Series Models < C2 - Econometric Methods: Single } \\
\text { Equation Models < C - Mathematical and Quantitative Methods, D83 } \\
\text { and Uncertainty < D - Microeconomics, D84 - }<\text { D8 - Information } \\
\text { Expectations|Speculations < D8 - Information and Uncertainty < D } \\
- \text { Microeconomics }\end{array}$ \\
\hline Keywords: & learning models, inflation expectations, survey data \\
\hline
\end{tabular}




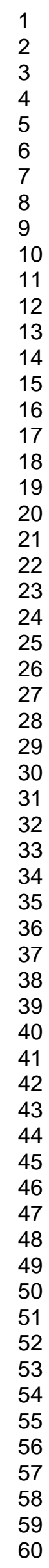

\section{SCHOLARONE ${ }^{m}$ \\ Manuscripts}

7

25

26

27

29

30

32

33

34

35

36

37

39

40

41

42

44

45

46

47

48

49

50

52

53

54

56

57

58

60 


\title{
Modelling the General Public's Inflation Expectations Using the Michigan Survey Data
}

Running title: Modelling the General Public's Inflation Expectations

\author{
Arto Luoma \\ arto.luoma@uta.fi \\ Department of Mathematics Statistics and Philosophy \\ 33014 University of Tampere, Finland \\ Jani Luoto \\ School of Business and Economics \\ P.O. Box 35, FIN-40014 University of Jyväskylä, Finland
}

\begin{abstract}
:
In this paper we discuss a few models developed to explain the general public's inflation expectations formation and provide some relevant estimation results. Furthermore, we suggest a simple Bayesian learning model which could explain the expectations formation process on the individual level. When the model is aggregated to the population level it could explain not only the mean values, but also the variance of the public's inflation expectations. The estimation results of the mean and variance equations seem to be consistent with the results of the questionnaire studies in which the respondents were asked to report their thoughts and opinions about inflation.
\end{abstract}

Keywords: learning models, inflation expectations, survey data 


\section{Introduction}

The inflation expectations of the general public are an important determinant of inflation and other macroeconomics fundaments, since they at least influence the process of wage bargaining, price setting and speculative buying. For example, higher inflation expectations may lead employees to demand higher wage settlements, push firms to a rise the prices of their products, and encourage agents to purchase more commodities. In addition, public concern about actual inflation has even certainly had an impact on political elections - see Cartwright and Delorme (1985), Parker (1986), Golden and Poterba (1989), Cuzan and Bundrick (1992), Fair (1994) and Shiller (1997). Thus, the inflation expectations of the general public play an essential role in modern market economies.

The assumption of rational expectations, which presumes that the agents know the true structure and probability distribution of the economy, is most commonly used in theoretical and empirical exercises today. However, having observed problems with this assumption, ${ }^{1}$ researchers have started to search alternative models for the expectations formation process. For example, in the models of limited information flows, developed by Mankiw and Reis (2002) and Sims (2003), the agents have rational expectations but are not based on complete information, while in the boundedly rational learning models they behave as professional scientists and use methods of scientific inference (see Sargent (1993) and Evans and Honkapohja (2001) for surveys). The reader should note that when these models are used, it is important to distinguish between the expectations

\footnotetext{
${ }^{1}$ see for example Zarnowitz (1985), Bonham and Cohen (1995), Jeong, Jinook, and G. S. Maddala (1996) and Lloyd (1999)
} 
of ordinary people and professionals, because these two groups use different methods and resources to form their expectations (for example, see results of Schiller, 1997).

In recent empirical literature of inflation expectations formations, Branch (2004 a) developed a promising model of heterogeneous agents, in which the general public forms its inflation expectations using a prediction function from a set of costly alternatives. Specifically, he assumes that consumers use three alternative types of forecast functions in their formation process: VAR, adaptive and naïve type models. His relatively contradictory results have lead scientists to think more closely about the process of consumers' inflation expectations formation. We, for example, find the assumption that households have access to VAR estimates to be unrealistic ${ }^{2}$. This is because the ordinary person cannot perceive the causes of inflation. Shiller (1997) in his questionnaire study, asks the respondents to list causes of inflation. The responses to this question were diverse and almost equally represented. Most assumed 'factors' of inflation were of a general type, such as 'greedy' or 'government'. Thus, identification of any more or less complex econometric or economic models seems to be an overwhelming task for ordinary people. In addition, we of course agree with Branch (2004 a) and many others in that the agents are heterogeneous. However, we believe that heterogeneity is mainly concerned with the thought process of individuals and is therefore hardly identifiable. More importantly, it is unclear how important this heterogeneity is in the evolution of aggregate consumer expectations.

Carroll (2003) explores the causality of the Michigan households' mean inflation expectations and the Survey of Professional Forecasters (SPF) mean inflation forecasts.

\footnotetext{
${ }^{2}$ One may assume that the VAR forecasts are almost same as the forecasts of professionals made available to the public trough news articles, but they cannot be directly compared since there is no cost to read those news articles.
} 
Using the standard Granger causality test he finds that the professional forecast Granger-causes the household forecast, but that there is no Granger causality in the opposite direction. This evidence of Granger causality plays an essential role in his theory of epidemiological expectations formation. In his epidemiology model, households form their expectations when they randomly come into contact with the relevant information set which Carroll assumed to consist of news articles about professional forecasters' forecasts. This epidemiology model is closely linked to the sticky information model of Mankiw and Reis (2002), for which Khan and Zhu (2002) and Mankiw, Reis and Wolfers (2003) acquire empirical estimates. All these authors employ different identification schemes, and estimate that individuals update their information sets on average every 12 months. If this is the case, a large proportion of the population always uses lagged news media forecasts as their information set. Consequently, inflation expectations of the general public should be modelled as a function of lagged professional expectations. Finally, Branch (2004 b) compares these 'sticky information' models to the model uncertainty approach of Branch (2004 a) and states that model uncertainly is a more robust element of the Michigan data.

In this paper, we show that the Michigan inflation expectations data support neither Carroll's epidemiological model nor the sticky information model of Mankiw and Reis (2002). Moreover, we suggest a simple Bayesian learning model for the formation process of inflation expectations and show that by using this type of a boundedly rational model we can describe individuals' opinions and their uncertainty about them. When the model is aggregated from the individual to national level and certain assumptions are made it can explain not only the mean values, but also the variance of the public's inflation expectations. The estimation results of the mean and variance 
equations seem to be consistent with the results of the questionnaire studies in which the respondents were asked to report their thoughts and opinions about inflation.

In the inflation expectations literature, there has been almost no work testing learning models using actual empirical data. An important exception is Caskey (1985), who in his excellent paper uses a learning model, similar to ours, for professional forecasters' views about future inflation. However, formation of inflation expectations requires these professionals to assimilate media reports, personal observations, macroeconomic data, and other forms of information that might be generated in obscure ways. Therefore, the use of an econometric model or some simple alternative behaviour model to explain their expectation formation might be problematic (see Manski, 2004). However, the expectation formation of the general public is likely more straightforward. A typical individual observes inflation through news media reports, which are mainly based on annualized monthly inflation figures, and perceives the process of inflation on a very superficial level. Thus, modelling inflation expectations using a simple, welldefined random process might be ideal in this case.

Our report is organized as follows. In Section II, we explore the empirical relationship between the professionals' and consumers' forecasts. In Section III, we discuss the formation process of the general public's inflation expectations and present a Bayesian learning model. In Section IV, we test how well the outcomes of this model can explain the mean and variance of inflation expectations. Finally, in Section V we conclude the paper. 


\section{Exploring the Relationship Between the Professionals' and Households' Forecasts and Monthly Inflation}

The most commonly published economic news articles for the general public likely concern the annualized monthly inflation figures

$$
\Pi_{t}^{m}=1200 \times \ln \left(\frac{C P I_{t}}{C P I_{t-1}}\right),
$$

where CPI is the seasonally adjusted Consumer Price Index for all urban consumers. However, every month, the Survey Research Center at the University of Michigan asks a random sample of at least 500 households the following question: 'During the next 12 months, do you think that prices in general will go up, or go down, or stay where they are now?'. If a respondent expects that the prices will change during the next 12 months then he is simply asked to supply a twelve months ahead forecast for annual inflation

$$
\Pi_{t}=100 \times \ln \left(\frac{C P I_{t}}{C P I_{t-12}}\right) .
$$

This provides us with a well-defined absolute numerical scale for responses; hence, the respondents understand what the survey questions mean and interpret them similarly. Thus, modelling the Michigan households' responses is sensible; see Manski (2004) for further discussion on the topic. 
We use the quarterly means of the above series, since the only relevant candidate series for the views of professional forecasters which has the same forecasting horizon as the Michigan series is the four-quarter inflation forecast from the Survey of Professional Forecasters conducted by the Federal Reserve Bank of Philadelphia ${ }^{3}$. Moreover, we use here only so-called real-time series, i.e. series which were available to the public when they formed their beliefs about future inflation. Our main source of data is the Federal Reserve Bank of Philadelphia ${ }^{4}$ (see Croushore and Stark, 2001). The missing values of the CPI data were acquired from Norman R. Swanson's home pages ${ }^{5}$.

To explore the relationship between the professionals' and households' forecasts and monthly inflation we start our analysis by estimating Carroll's (2003) equation (12) with constant term and recently published annualized monthly inflation $\Pi_{t}^{m}$ (not annual inflation as in Carroll),

$$
M_{t}\left[\Pi_{t+4}\right]=\gamma_{0}+\gamma_{1} S_{t}\left[\Pi_{t+4}\right]+\gamma_{2} M_{t-1}\left[\Pi_{t+3}\right]+\gamma_{3} \Pi_{t}^{m}+v_{t}
$$

where $M_{t}$ and $S_{t}$ are operators that yield the population means (or medians) of the Michigan and SPF inflation expectations at time $\mathrm{t}$, respectively, and $v_{\mathrm{t}}$ is an error term. The estimates obtained using the mean and median series are presented in Table 1.

The estimates of $\gamma_{3}$ in the mean and median cases are positive and significant at the $5 \%$ and $1 \%$ levels, respectively. This suggests that annualized monthly inflation, which is the most commonly reported inflation figure in the news media, is an important factor to

\footnotetext{
${ }^{3}$ data are available at http://www.phil.frb.org/econ

${ }_{5}^{4}$ data are available at http://www.phil.frb.org/econ/forecast/readow.html

${ }^{5}$ data are available at http://econweb.rutgers.edu/nswanson/realtime.htm
} 
Surprisingly, when we look at the estimate of $\gamma_{2}$ in the median case, its estimate is not statistically significant. Therefore, we could possibly exclude the lagged value of the Michigan series from the regression equation (3). This empirical finding causes a real problem to Carroll's epidemiology model. Moreover, the reader should note that as Curtin (1996) and Mankiw, Reis and Wolfers (2003) argue, the long tails of the Michigan expectation series are not particularly informative and, therefore, the results acquired using median values might be more sensible. Therefore, in the following we will focus on the median values of the Michigan series.

Carroll (2003) argues that the constant term in equation 3 is spuriously significant because it implies, for example, that if both actual inflation and the professional's expectations were to go to zero forever, people would continue to expect a positive inflation rate forever i.e. they wouldn't eventually learn. However, this is only true when we expect that individuals form their expectations as Carroll assumes. For example, if individuals form their expectations using learning models, the presence of a positive constant in regression poses no problem. 
Unfortunately, the results presented above are not very reliable, because using nonstationary time series in regression analysis may yield spurious regression and inconsistent parameter estimates (see, for example, Hamilton, 1994). On the other hand, if the series are cointegrated, the ordinary least squares (OLS) estimates might be biased due to endogeneity and serial autocorrelation (see Banerjee et al, 1993, Chapter 7). Therefore, we studied whether the series are unit root processes. The results of the augmented Dickey-Fuller test are shown in Table 2. Since the null hypothesis of a unit root is not rejected in either case of an expectation series and only slightly rejected in the case of the annualized inflation series, we model them as I(1) processes.

If the expectations series move together in the long-run, which seems to be a reasonable assumption, they can be modelled using co-integrated vector autoregression (CVAR). Let therefore $y_{t}=\left(M_{t}\left[\Pi_{t+4}\right] S_{t}\left[\Pi_{t+4}\right] \Pi_{t}^{m}\right)^{\prime}$ ' be the vector of the SPF median inflation forecast, the Michigan household median inflation expectation and annualized monthly inflation, respectively. Then the CVAR model can be parameterized in the error correction form

$$
\Delta y_{t}=\psi+\sum_{i=1}^{p-1} \Gamma_{i} \Delta y_{t-i}+\alpha \beta^{\prime} y_{t-1}+\varepsilon_{t},
$$

where $\psi$ is a vector of parameters, $\alpha$ a matrix/vector of adjustment coefficients, $\beta$ a cointegrating matrix/vector and $\Gamma_{\mathrm{i}}: \mathrm{s}$ parameter matrices. The error vectors $\varepsilon_{\mathrm{t}}$ are assumed to be independent over time and normally distributed with zero mean and covariance matrix $\Omega^{6}$.

\footnotetext{
${ }^{6}$ Note that we do not assume the SPF nor inflation series to be exogenous. For example, even if the lagged values of the Michigan series do not help forecast the future SPF values, one should not take this
} 
We will use the Bayesian approach and posterior density simulations to make exact inference on the parameters. To see whether the data confirm the existence of a cointegrating relation between the Michigan, professional and actual inflation series and to find proper lag length for the model (4) we follow Corander and Villani (2004) and compute approximate fractional marginal likelihoods (FML). The FML results (not reported here in order to save space) indicate that the proper lag length is 1 and cointegration rank 2.

However, we restrict our model to include only one co-integrating vector and write the long-run relationship in an informative form

$$
M_{t}\left[\Pi_{t+4}\right]=\beta_{1} S_{t}\left[\Pi_{t+4}\right]+\beta_{2} \Pi_{t}^{m}+\mathrm{z}_{\mathrm{t}}
$$

where $z_{t}$ is a stationary term; that is, we use the parametrisation $\beta=\left(-1 \beta_{1} \beta_{2}\right)^{\prime}$. From the estimates of $\beta_{1}$ and $\beta_{2}$ we can see which of the series $S_{t}\left[\Pi_{t+4}\right]$ or $\Pi_{t}^{m}$ is more closely related to the Michigan series.

In order to generate conditional and marginal posteriors, we use normal likelihood and an improper prior $p\left(\Psi, \alpha, \beta, \Gamma_{1}, \ldots, \Gamma_{p-1}, \Omega\right) \propto|\Omega|^{-0.5(m+1)}$ in our Bayesian analysis. With this choice of prior the joint posterior distribution of $\beta_{1}$ and $\beta_{2}$ has a $1-1$ poly-t density (see Corollary 3.1 in Bauwens and Lubrano, 1996) and we can use the algorithms of Richard and Tompa (1980) to generate random numbers from it.

as a sign of noncausality, since professional forecasters should use the information offered by consumer expectations when they form their forecasts. For example, they might expect that the high inflation expectations of the general public cause consumer inflation to rise. 
The estimates of the CVAR model are presented in Table 1. Since more than $4 \%$ of the probability mass of $\beta_{1}$ lies below zero, one must be careful when stating that the general public uses professional forecasters' forecasts when they form their expectations. On the other hand, the high CVAR estimate $\beta_{2}=0.349$ confirms our earlier results that annualized monthly inflation is an important factor in the public's inflation expectations formation process. One can also interprete the estimated cointegrating relation so that the expectations of the public are more closely connected to annualized monthly inflation figures than the professionals' forecasts, since professionals also use other information in their forecasts, such as unemployment rates and lagged inflation estimates. See also the estimates of equation (6) in Table 1, where annualized inflation is excluded from regression. The link between the Michigan and SPF expectations does not seem strong here either, since the $95 \%$ posterior interval of $\beta_{1}$ includes zero.

Khan and Zhu (2002), Mankiw, Reis and Wolfers (2003) and Carroll (2003) acquire empirical estimates which indicate that in sticky information models, individuals update their information sets on average every 12 months. If this is the case, the resulting median forecast of the Michigan survey should be closely related to the median of geometrically-weighted averages of past professional inflation forecasts and the cross coefficients of the lagged SPF series and their sum $\Sigma \gamma_{21}{ }^{(i)}$ should be different from zero. Therefore, we estimated the CVAR model of equation (4) with data $y_{t}=\left(M_{t}\left[\Pi_{t+4}\right] S_{t}\left[\Pi_{t+4}\right]\right)$ and cointegrating relationship

$$
M_{t}\left[\Pi_{t+4}\right]=\beta_{1} S_{t}\left[\Pi_{t+4}\right]+\mathrm{z}_{\mathrm{t}}
$$


The FML based estimates for rank support this restriction (rank = 1) and the estimated lag length is 1 . However, because we are interested in the coefficients of the lagged SPF series and their sum $\left(\sum \gamma_{21}{ }^{(i)}\right)$ we estimate the CVAR model using four lags.

The estimates of this model are shown in Table 1 (equation (6)). As the lag length estimate indicates, the posterior density of $\Sigma \gamma_{21}{ }^{(i)}$ has a lot of its probability mass close to zero. Thus, the cumulative effect of the lagged SPF series on the Michigan series is not economically or statistically significant ${ }^{7}$. It seems that the data do not support Carroll's (2003) epidemiology model nor Mankiw's and Reis's (2002) sticky information model.

Finally, Table 3 shows the medians and standard errors of the cross coefficients $\gamma_{21}(i)$ (i $=1, \ldots, p)$ and their sums when standard Bayesian vector autoregressive (BVAR) models with a noninformative Jeffrey's prior distribution and different lag lengths ${ }^{8}$ are used. We can see from the table that the parameters $\gamma_{21}(i)$ are not significantly different from zero except in the model with one lag. However, as Carroll's Granger causality test indicates, the cumulative effect of the SPF forecast on the Michigan series is positive with high probability. Thus, there seems to be a relation between the professional's and the general public's forecasts, but this relation is probably a kind of long-run comovement in which the general public adjusts its expectations as the significant estimate for the adjustment parameter $\alpha_{1}=0.487$ indicates (see Equation 6 in Table 1). However, households do not necessarily adjust their expectations toward the forecasts

\footnotetext{
${ }^{7}$ Note also that no one of the parameters $\gamma_{21}{ }^{(i)}$ had a posterior distribution deviating significantly from zero (results were similar when we use mean series). We also estimated the error correction model with the assumption that the SPF series is exogenous and the results looked similar.

${ }^{8}$ The model is of the form $y_{t}=\sum_{i=1}^{p} \Gamma_{i} y_{t-i}+\varepsilon_{t}$, where $\Gamma_{\mathrm{i}}$ :s are parameter matrices and $\varepsilon_{\mathrm{t}}$ is the normally distributed error term with zero mean and $\Sigma$ covariance.
} 
of professionals. Rather, both professionals and the general public adjust their expectations toward actual annual inflation i.e. both groups correct their expectations toward the fully rational outcome.

In summary, we do not find that the data support Carroll's (2003) epidemiology model or Mankiw's and Reis's (2002) sticky information model. Therefore, there is a need for some alternative theory for the general public's inflation expectations.

\section{Modelling the Consumers' Formation of Inflation Expectations}

In our candidate theory, which offers an alternative explanation for the general public's inflation expectations formation process, we assume that each individual has his own personal beliefs about the process of inflation. They update this prior knowledge regularly using annualized monthly inflation figures and possibly some other variables offered by the news media and use the updated information to form their expectations. We find several reasons why inflation expectations of the general public should modelled using a well-defined random process with personal probabilities about the parameter values of the process. Firstly, individuals cannot observe inflation directly but through the news media, since in everyday life they observe the prices not the inflation. Secondly, it is well known that typical individuals' views about the inflation process are relatively poor. They may not have any clear idea about the causes of inflation. It is very descriptive that the most common answer was 'greed' or 'greedy', when Shiller (1997), in his questionnaire study, asked people to list the causes of inflation. Thirdly, we, unlike Mankiw and Reis (2002) or Carroll (2003), expect that most people follow economic news daily or at least regularly. We agree with Shiller (1997) who argues: "Because the word "inflation" is so much a part of everyday lives, it has many 
associations and connotations to ordinary people. Moreover, because shopping, and thereby noticing prices, is an everyday activity for ordinary people, thinking about prices is also a major part of people's thinking, and the subject "inflation" is one of great personal interest for most people'. Furthermore, when Shiller (1997) asked people if they find news stories about inflation interesting, $89 \%$ reported that inflation news reports are very or somewhat interesting (see more discussion on individuals' expectation behaviour: Kahneman and Tverky, 1979, Nisbett and Ross, 1980, Gleitman, 1996, Mahmoud, El-Gamal and Grether, 1995, Shiller, 1997, Akerlof, Dickens and Perry, 2000, and Manski, 2004). Therefore, we assume that a typical individual believes that the process of inflation is captured by the model

$$
\Pi_{t}=X_{t-4} B+\varepsilon_{t},
$$

where $\varepsilon_{\mathrm{t}}$ is a normally distributed error term with zero mean and $\sigma^{2}$ variance and $\mathrm{X}_{\mathrm{t}-4}$ is a row vector which includes annualized monthly inflation and other possible explanatory variables. We believe that a simple univariate process describes the public's views about the process of inflation better than a multivariate process, since ordinary people seem to fail to understand the concept of general equilibrium (see Shiller, 1997).

However, the opinions about the parameter values of the above process may vary strongly among individuals. To allow for this kind of disagreement, we further assume that every individual has his own personal beliefs about the parameters of the model (7). Moreover, we assume that the personal prior distribution of the $i$ th individual for the parameter vector $\mathrm{B}^{\mathrm{i}}$ is multivariate normal: 


$$
B^{i} \sim N\left(B_{0}^{i}, \sigma^{2}\left(V_{0}^{-1}\right)^{i}\right)
$$

where $\mathrm{B}_{0}$ is the individual's prior estimate of $\mathrm{B}$ and matrix $\left(V_{0}^{-1}\right)^{i}$ is a measure of his uncertainty, relative to $\sigma^{2}$. If, for example, the $i$ th individual believed that inflation follows a random walk process, the parameter of recent inflation in $\mathrm{B}_{0}$ would be equal to 1 and the corresponding diagonal entry in $V_{0}^{-1}$ very small. The parameters of other variables in $\mathrm{B}_{0}$ would be zero and the corresponding variances in $V_{0}^{-1}$ very small. Thus we have a very flexible behavioural model which covers the observed disagreement about the causes of inflation and explains the variance of inflation expectations among households (see Shiller, 1997, and Mankiw, Reis and Wolfers, 2003).

We further assume that the $i$ th individual forecasts inflation on the basis of his evolving beliefs about B (confer Caskey, 1985). Each period he obtains new information on annualized monthly inflation and other possible explanatory variables from news articles he uses it to update his beliefs about the parameter vector B. This updating process can be best described using the following recursive equations of the Kalman filter:

$$
\begin{aligned}
& \hat{B}_{t}^{i}=\hat{B}_{t-1}^{i}+K_{t}\left(\Pi_{t}-X_{t-4} \hat{B}_{t-1}^{i}\right) \\
& \left(\hat{V}_{t}^{-1}\right)^{i}=\left(\hat{V}_{t-1}^{-1}\right)^{i}-K_{t}^{i} X_{t-4}\left(\hat{V}_{t-1}^{-1}\right)^{i} \\
& K_{t}^{i}=\left(\hat{V}_{t-1}^{-1}\right)^{i} X_{t-4}^{\prime}\left(X_{t-4}\left(\hat{V}_{t-1}^{-1}\right)^{i} X_{t-4}^{\prime}+1\right)^{-1}
\end{aligned}
$$


where vector $\mathrm{K}_{\mathrm{t}}$ is the so-called Kalman gain. We do not expect that individuals fully remember the observations of possible explanatory variables, presented in past news articles; however, our point is that this kind of a recursive system might be the best description of their learning process. The model also covers the possibility that some people have such strong prior beliefs that they do not change them.

Finally, assuming that the $i$ th individual uses a quadratic loss function in his forecasts and taking into consideration that his thought processes cannot be fully replicated, we model his inflation expectations as

$$
E_{t}^{i}\left(\Pi_{t+4}\right)=X_{t} \hat{B}_{t}^{i}+u_{t}^{i}
$$

where the operator $E_{t}^{j}$ denotes the $i$ th individual's expectation at time $\mathrm{t}$ and $\mathrm{u}_{\mathrm{t}} \mathrm{a}$ normally distributed error with zero mean and $\sigma_{u}^{2}$ variance. Unfortunately, because of the nature of consumer surveys, such as the Michigan survey data, we cannot test the Bayesian learning model directly. The reason is that consumer surveys use random samples of respondents and the respondents are different every month. Therefore, it is not possible to track individual learning processes using the data. However, the Bayesian learning model has a couple of consequences which we can test empirically. Firstly, the model implies that the mean of the expectations can be calculated as

$$
m\left\{E_{t}^{i}\left[\Pi_{t+4}\right]\right\}=X_{t} m\left\{\hat{B}_{t}^{i}\right\}+m\left\{u_{t}^{i}\right\}
$$


where $m\{\}$ denotes mean over all individuals in the population. Secondly, the variance of expectations is given by

$$
\operatorname{Var}\left(E_{t}^{i}\left[\Pi_{t+4}\right]\right)=X_{t} \operatorname{cov}\left(\hat{B}_{t}^{i}\right) X_{t}{ }^{\prime}+\operatorname{var}\left(u_{t}^{i}\right)
$$

where $\operatorname{cov}\left(\hat{B}_{t}^{i}\right)$ is the covariance matrix measuring the dispersion of opinions among the general public.

Equation (13) implies that the population variance of inflation expectations is a function of annualized monthly inflation and possibly some other variables reported in the news media and of the variances and covariances of the individuals' parameter estimates.

\section{Empirical test of the Bayesian Learning Model}

The respondents of the monthly Michigan surveys have learning paths with different lengths and starting points. Therefore, it seems reasonable to assume that the mean vector $m\left\{\hat{B}_{t}^{i}\right\}$ and dispersion matrix $\operatorname{cov}\left(\hat{B}_{t}^{i}\right)$ in equations (13) and (14) stay constant over time. Then we can estimate them using OLS. However, the reader should note that we can not trust the standard t-statistics related to these parameters, since the time series involved in these models are unit root or nearly unit-root processes. However, our main objective is to investigate how well the outcomes of the Bayesian learning model can predict the mean and variance series of the actual Michigan inflation expectations. We 
suggest that the key things here are the correct signs of the variance estimates and the prediction power of the estimated models. To proceed further, we set ${ }^{9}$

$$
\operatorname{var}\left(M_{t}\left[\Pi_{t+4}\right]\right)=\operatorname{var}\left(E_{t}^{i}\left[\Pi_{t+4}\right]\right)+\text { error }=X_{t}^{\prime} \operatorname{cov}\left(\hat{B}_{t}^{i}\right) X_{t}+\operatorname{var}\left(u_{t}^{i}\right)+\text { error }
$$

$M_{t}\left[\Pi_{t+4}\right]=m\left\{E_{t}^{i}\left[\Pi_{t+4}\right]\right\}+$ error $=X_{t} m\left\{\hat{B}_{t}^{i}\right\}+m\left\{u_{t}^{i}\right\}+$ error.

Moreover, we assume that the most probable components of $\mathrm{X}_{\mathrm{t}}$ are annualized monthly inflation $\Pi_{\mathrm{t}}^{\mathrm{m}}$ and the 3-month T-bill rate, since most commonly published economic news articles on the subject concern these figures and since the public seems to perceive the relation between inflation and the interest rate (Shiller, 1997). Our alternative candidate series, which may compensate for the T-bill series, are those which are most probably regularly reported by all major media in the US:
a) SPF forecast
b) Unemployment rate
c) Annualized quarterly growth of GDP
d) Annualized monthly growth of M1

The results for the variance and mean equations are summarized in Table 4 . We can see that the variance model based on inflation and the 3-month T-bill rate and the variance model based on inflation alone give similar correlations between the predicted variance

\footnotetext{
${ }^{9}$ To analyze the predicted variance of the learning model we need a longer sample period than the period 1981/3-2004/1 for which the professionals' CPI inflation forecast series is available. To obtain a longer forecast period 1970/1-2004/1 we used SPF's GDP deflator forecast series. We regressed the CPI inflation forecast series on the GDP deflator inflation forecast series and a constant and predicted the CPI inflation forecast series for the period 1970/1-1981/2 using the estimated regression model. The parameter estimates were 0.68 and 0.89 for the constant and the GDP deflator forecast series, respectively).
} 
series and the actual Michigan variance. However, the actual mean series has a remarkably higher correlation with the predicted mean series based on inflation and the T-bill rate than with the predicted series based on inflation alone. These results suggest that a part of the population always believes the process of inflation to be random walk, which causes the variance of the Michigan survey to be high, while another part of them is aware of the relationship between inflation and the interest rate (confer Shiller, 1997).

The model based on monthly inflation and the 3-month T-bill rate gives relatively high correlation coefficients between the predicted and actual Michigan mean series, compared to the models based on inflation and unemployment, inflation and the quarterly growth rate of GDP or inflation and the monthly growth rate of M1. The drop of the correlation coefficient from the mean model based on inflation and the T-bill rate to the mean model based on inflation and the unemployment rate is quite large, about $11 \%$. Moreover, the correlation between the predicted mean series based on annualized monthly inflation and the actual Michigan mean series is 0.645 , which suggests that the growth of money, growth of GDP or unemployment series add practically nothing to the learning model expectations based on monthly inflation (compare correlations reported in Table 4). These findings are in line with Shiller's (1997) questionnaire study, in which he observes that most people seem to fail to think of economic models; people do not tend to see any connection between inflation and unemployment, i.e. the Phillips curve, or between inflation and money growth, i.e. the quantity theory of money.

The variance model based on inflation and unemployment and the model based on inflation and the SPF series give us the highest correlations between the predicted and actual variance series $(0.88$ and 0.9$)$. However, if we take a closer look at the parameter 
estimates of these models, we find that in both these models the estimates of $\operatorname{var}(u)+\operatorname{var}\left(b_{0}\right)$ are negative, which of course does not make sense. One plausible explanation for the high correlation between the professionals' forecast series and the Michigan variance series $\left(\operatorname{cov}\left(b_{2}, b_{0}\right)=14.7\right)$ is that there is a higher probability for individuals who believe inflation to be random walk to give lousy forecasts when inflation is rationally expected to increase rapidly than during a stable low inflation period.

In summary, based on the weak relation between the SPF and Michigan median series, as found when estimating equations (5) and (6) in Section 2, and the results presented in the current section, we conclude that a Bayesian learning model based on annualized monthly inflation series and the 3-month T-bill rate offers us a more plausible explanation for the general public's inflation expectations than the limited information flows models based on rational or nearly rational forecast series.

\section{Conclusion}

In this paper, we have empirically shown that a simple Bayesian learning model is a feasible explanation for the general public's inflation expectations formation. We have also shown that the Michigan Survey data do not support models of limited information flows, discussed the theoretical basis of the Bayesian model and come to the conclusion that it gives a more realistic picture of individuals' expectation behaviour in the case of inflation than some new models presented in the literature, such as models of limited information flows or models with uncertainty approach. Learning models have, of course, many variants, but the advantage of Bayesian models is that by using personal 
probabilities, one can describe individuals' opinions and their willingness to update them. From our point of view, Bayesian learning models are worth further development in the context of the public's inflation expectations. 
Model

$$
M_{t}\left[\Pi_{t+4}\right]=\gamma_{0}+\gamma_{1} S_{t}\left[\Pi_{t+4}\right]+\gamma_{2} M_{t-1}\left[\Pi_{t+3}\right]+\gamma_{3} \Pi_{t}^{m}+v_{t}
$$

\begin{tabular}{lccccc}
\hline \multicolumn{1}{c}{ Equation } & $\gamma_{0}$ & $\gamma_{1}$ & $\gamma_{2}$ & $\gamma_{3}$ & $\mathrm{R}^{2}$ \\
(3) with mean & $1.176^{* * *}$ & $0.510^{* * *}$ & $0.233^{* *}$ & $0.042 * *$ & 0.849 \\
series & $(0.181)$ & $(0.080)$ & $(0.090)$ & $(0.019)$ & \\
(3) with median & $1.324 * * *$ & $0.386^{* * *}$ & 0.074 & $0.079 * * *$ & 0.794 \\
series & $(0.145)$ & $(0.059)$ & $(0.112)$ & $(0.020)$ &
\end{tabular}

Model (VECM)

$\Delta y_{t}=\psi+\sum_{i=1}^{p-1} \Gamma_{i} \Delta y_{t-i}+\alpha \beta^{\prime} y_{t-1}+\varepsilon_{t}$, where $\mathrm{y}_{\mathrm{t}}=\left(\mathrm{M}_{\mathrm{t}}\left[\Pi_{\mathrm{t}+4}\right] \mathrm{S}_{\mathrm{t}}\left[\Pi_{\mathrm{t}+4}\right] \Pi_{\mathrm{t}}{ }^{\mathrm{m}}\right)^{\prime}$ and the cointegrating relation is $M_{t}\left[\Pi_{t+4}\right]=\beta_{1} S_{t}\left[\Pi_{t+4}\right]+\beta_{2} \Pi_{t}^{m}+z_{t}$

$\begin{array}{ccc}\text { Equation } & \beta_{1} & \beta_{2} \\ (5) & 0.149 & \mathbf{0 . 3 4 9} \\ & 95.2 \% & 100 \%\end{array}$

Model (VECM)

$\Delta y_{t}=\psi+\sum_{i=1}^{p-1} \Gamma_{i} \Delta y_{t-i}+\alpha \beta^{\prime} y_{t-1}+\varepsilon_{t}$, where $\mathrm{y}_{\mathrm{t}}=\left(\mathrm{M}_{\mathrm{t}}\left[\Pi_{\mathrm{t}+4}\right] \mathrm{S}_{\mathrm{t}}\left[\Pi_{\mathrm{t}+4}\right]\right)^{\prime}$ and the cointegrating relation is $M_{t}\left[\Pi_{t+4}\right]=\beta_{1} S_{t}\left[\Pi_{t+4}\right]+z_{t}$

$\begin{array}{ccccc}\text { Equation } & \Sigma \gamma_{21}{ }^{(i)} & \beta_{1} & \alpha_{1} & \alpha_{2} \\ (6) & -0.500 & 0.418 & \mathbf{0 . 4 8 7} & 0.223 \\ & 84.0 \% & 96.9 \% & 98.7 \% & 95.5 \%\end{array}$

Newey-West standard errors in parentheses. The results are not sensitive to the choice of lags (4 lags are used). The signs $* *, *$ and ${ }^{\bullet}$ denote statistical significance at the $1 \%, 5 \%$ and $10 \%$ levels, respectively. In the Bayesian analysis part we report the posterior median and the share of posterior mass which lies above (below) zero when the median is positive (negative). The median is given in bold face when zero is not included in the $95 \%$ posterior interval).

Table 2: Augmented Dickey-Fuller Tests

Augmented Dickey-Fuller Test for Michigan Median Inflation Expectations Series, Professional Forecasters' Inflation Forecast Series and annualized monthly inflation series.

\begin{tabular}{lc}
\hline \multicolumn{1}{c}{ Variable } & $\mathrm{t}$-adf \\
Michigan mean series & -1.993 \\
Michigan median series & -1.529 \\
Survey of Professional Forecasters mean series & -0.5551 \\
Survey of Professional Forecasters median series & -0.7668 \\
Annualized monthly inflation (Realtime) & $-3.201 *$ \\
\hline \multicolumn{2}{c}{ Sample 1981/Q3 - 2004/Q1 } \\
* indicates statistical significance at the level of 5\% \\
\hline
\end{tabular}


Table 3: Point Estimates of BVAR Models

Model

$$
y_{t}=\sum_{i=1}^{p} \Gamma_{i} y_{t-i}+\varepsilon_{t}
$$

with Jeffrey's Prior and Different Lag Lengths $(\mathrm{p}=1, \ldots, 4)$ where $\mathrm{y}_{\mathrm{t}}=\left(\mathrm{M}_{\mathrm{t}}\left[\pi_{\mathrm{t}+4}\right] \mathrm{S}_{\mathrm{t}}\left[\pi_{\mathrm{t}+4}\right]\right)^{\prime}$

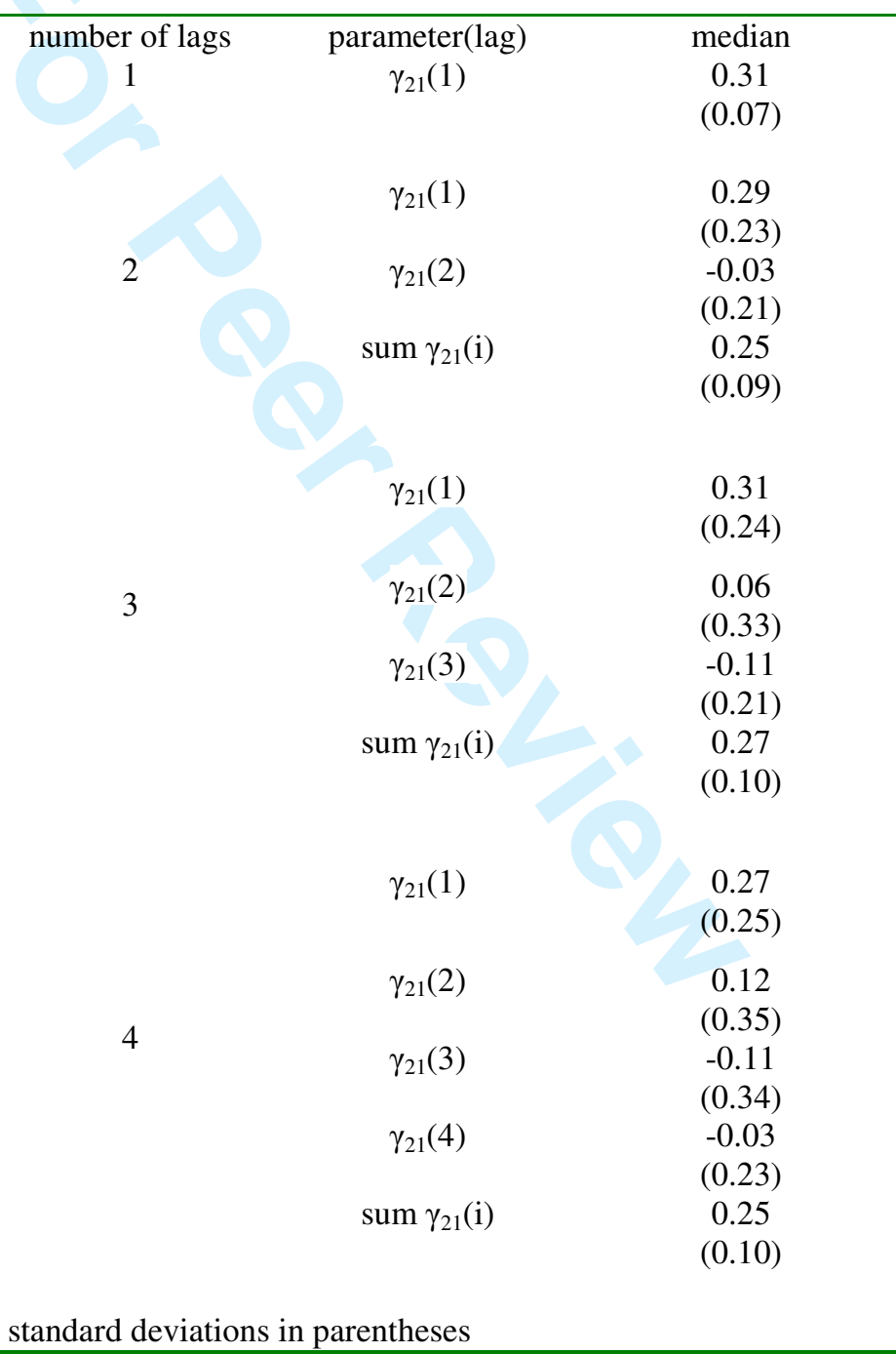

standard deviations in parentheses 
Table 4: Estimation Results for Variance and Mean Equations

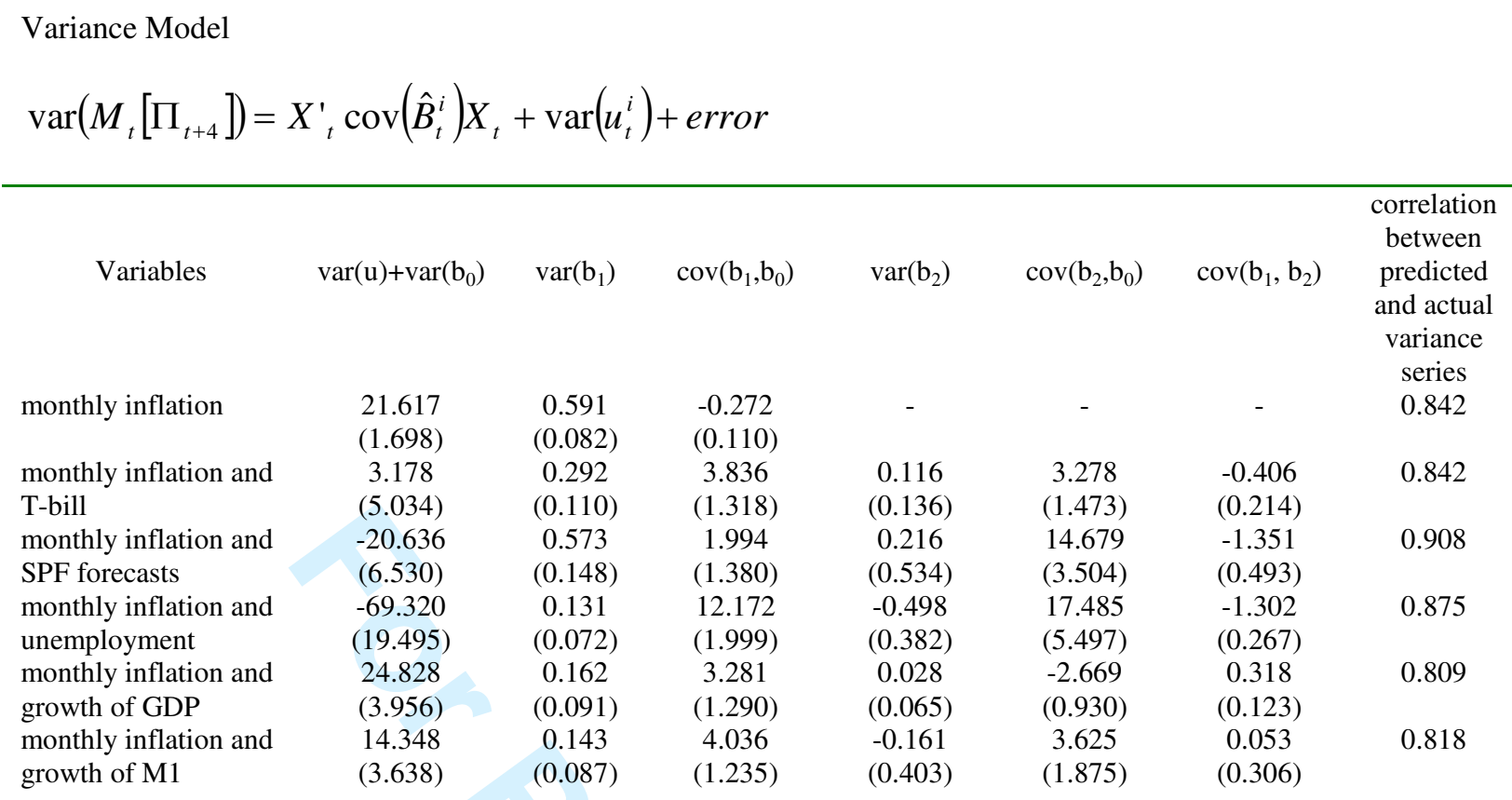

Mean Model

$$
M_{t}\left[\Pi_{t+4}\right]=X_{t} m\left\{\hat{B}_{t}^{i}\right\}+m\left\{u_{t}^{i}\right\}+\text { error }
$$

Variables

monthly inflation $\left(b_{1}\right)$

monthly inflation $\left(\mathrm{b}_{1}\right)$ and T-bill $\left(\mathrm{b}_{2}\right)$

monthly inflation and SPF forecasts

monthly inflation and unemployment

monthly inflation and growth of GDP

monthly inflation and growth of M1

\section{$\mathrm{b}_{0}$}

3.176

$(0.142)$

2.341

$(0.129)$

1.516

(0.130)

1.658

$(0.293)$

3.369

$(0.165)$

3.101

$(0.158)$ $\mathrm{b}_{1} \quad \mathrm{~b}_{2}$

0.295

$(0.037)$

0.149

$(0.023)$

0.054

(0.025)

0.270

(0.032)

0.291

(0.036)

0.298

(0.037) correlation between predicted and actual mean series 0.645

0.852

0.918

0.757

0.668

0.651 
References:

\begin{abstract}
Akerlof, G. A., Dickens, W. T. and Perry, G. L. (2000) Near-Rational Wage and Price Setting and the Optimal Rates of Inflation and Unemployment, Brookings Papers on Economic Activity.
\end{abstract}

Andrews, D. W. K. (1991) Heteroskedasticity and autocorrelation consistent covariance matrix estimation, Econometrica, 59, pp. 817-858.

Banerjee, A., J.J. Dolado, J.W. Galbraith, and D.F. Hendry (1993) Cointegration, Error Correction, and the Econometric Analysis of Non-Stationary Data, Oxford University Press

Berk, J. M. (1999) Measuring inflation expectations: a survey data approach, Applied Economics, 31, 1467-1480.

Branch, W. A. (2004a) The Theory of Rationally Heterogeneous Expectations:

Evidence from Survey Data on Inflation Expectations, Economic Journal, 114, 592621.

Branch, W. A. (2004b) Sticky Information and Model Uncertainty in Survey Data on Inflation Expectations, Working paper, College of William and Mary.

Bonham, C. and Cohen, R. H. (1995) Testing the Rationality of Price Forecasts: Comment, American Economic Review 85, 284-89.

Carlson, J. A. (1975) Are Price Expectations Normally Distributed? Journal of the American Statistical Association, 70, 749-754.

Carroll, C. D. (2003) Macroeconomic Expectations of Households and Professional Forecasters, Quarterly Journal of Economics, 269-298.

Caskey, J., (1985) Modeling the Formation of Price Expectations: A Bayesian Approach, The American Economic Review, 75, 768-776. 
Cartwright, P. A. and DeLorme, C. D. Jr. (1985) The Unemployment-Inflation Voter Utility Relationship in the Business Cycle: Some Evidence, Southern Economic Journal, 51, 898-905.

Croushore, D. and Stark, T. (2001) A Real-Time Data Set for Macroeconomists, Journal of Econometrics 105, 111-130.

Curtin, R. (1996) Procedure to Estimate Price Expectations, mineo, University of Michigan Survey Research Center.

Cuzan, A. G. and Bundrick, C. M. (1992) Selected Fiscal and Economic Effects on Presidental Elections, Presidental Studied Quarterly, 22, 127-134.

Corander, J. and Villani, M. (2004) Bayesian Assessment of Dimensionality in Reduced Rank Regression, Statistica Neerlandica, 58, 255-270.

Fair, R. C. (1978) The Effect of Economic Events on Votes for President, The Review of Economics and Statistics, 60, 159-173.

Fair, R. C. (1994) The Effect of Economic Events on Votes for President: 1992 Update, Cowles Foundation Discussion Paper No. 1084.

Forsells, M. and Kenny, G. (2002) The Rationality of Consumer's Inflation Expectations: Survey-Based Evidence for the Euro Area, European Central Bank Working Paper Series, No. 163.

Gleitman, Henry (1996) Basic Psychology, New York: Norton.

Golden, D. G. and Poterba, J. M. (1980) The Price of Popularity: The Political Business Cycle Reconsidered, American Journal of Political Science, 696-714.

El-Gamal, M. A. and Grether, D. M. (1995) Are People Bayesian? Uncovering Behavioral Strategies, Journal of the American Statistical Association, 90, 1137-1145. 
Hamilton, D. James (1994) Time series analysis, Princeton university press.

Evans, G. W. and Honkapohja S. (2001). Learning and Expectations in Macroeconomics, Princeton University Press.

Jeong, J. and Maddala G. S. (1996) Testing the Rationality of Survey Data Using the Weighted Double-Bootstrapped Method of Moments, Review of Economics and Statistics 78, 296-302.

Kahneman, D. and Tversky, A. (1979), Prospect Theory: An Analysis of Decision under Risk, Econometrica 47, 263-92

Khan, H. and Zhu Z. (2002) Estimates of the Sticky-Information Phillips Curve for the United States, Canada and the United Kingdom, Bank of Canada Working paper 200219, forthcoming Journal of Money, Credit and Banking.

Lloyd B. T. Jr. (1999) Survey Measures of Expected U.S. Inflation, Journal of Economic Perspective, 13, 125-144.

Manski C. F. (2004) Measuring Expectations, Econometrica, 72, 1329 -

Mankiw, N. G. and Reis R. (2002) Sticky Information Versus Sticky Prices: A Proposal to Replace the New Keynesian Phillips Curve, Quarterly Journal of Economics, 117, 1295-1328.

Mankiw, G. N. Reis R and Wolfers J. (2003) Disagreement About Inflation Expectations, NBER Macroeconomics Annual 2003.

Nisbett, R. and Ross L. (1980) Human Inference: Strategies and Shortcomings of Social Judgment, Englewood Cliffs, NJ: Prentice-Hall.

O’Hagan, A. (1995) Fractional Bayes factors for model comparison (with discussion), Journal of the Royal Statist. Society, Ser. B, 57, 99-138. 
Parker, G. R., (1978) Economic Partisan Advantages in Congressional Contests: 19381978, Puplic Opinion Quarterly, 50, 387-401.

Richark, J. F. and Tompa, H (1980). On the Evaluation of Poly-t Density Functions, Journal of Econometrics, 12, 335-351.

Sargent, T. J., (1993) Bounded Rationality in Macroeconomics, Oxford University Press, Oxford.

Sims, C. A. (2003) Implications of Rational Inattention, Journal of Monetary Economics, 50, 665-690.

Shiller, R. J. (1997) Why Do People Dislike Inflation, in Reducing Inflation: Motivation and Strategy, edited by Christina D. Romer and David H. Romer. Chicago: University of Chicago press.

Stock, J. H. and Watson, M. W. (1999) Forecasting inflation, Journal of Monetary Economics, 44, 293-335.

Zarnowitz, V. (1985) Rational Expectations and Macroeconomic Forecasts, Journal of Business \& Economic Statistics, 3, 293-311. 